\title{
Color Sensor Application on Electric Drives
}

\section{Aplikasi Sensor Warna pada Penggerak Listrik}

\author{
Risfendra ${ }^{1}$, M. Harun Rosyid ${ }^{1 *}$
}

\begin{abstract}
TCS3200 is one type of sensor that is able to identify various types of colors. Its ability to distinguish colors can be used as a selector and work controller on several electrical devices. To find out the benefits of TCS300 sensors, a study was conducted to find out the function of TCS3200 sensors in several movers and electrical devices. In this study a TCS3200 sensor application was made in the form of a DC 5V relay device (to start or stop the electric drive) and several electronic devices. This tool uses media in the form of color cards as data input. The card will be read by the TCS3200 sensor, after which the reading data will be received by the Atmega8535 microcontroller, then the results will be displayed on several application devices such as relays, LCD, speakers and LED as output. The sensor will work to read colors within a distance of $2.5 \mathrm{~cm}$ from the color object. After conducting research, the TCS3200 sensor can detect the color card that has been provided. Based on the program that has been compiled, the sensor is able to distinguish 9 types of colors and takes 1-2 seconds to activate the output after the color input is given.
\end{abstract}

Keywords

Color Sensor, Atmega8353, TCS3200 Sensor, Electric Drives

\begin{abstract}
Abstrak
TCS3200 adalah salah satu jenis sensor yang mampu mengidentifikasi berbagai jenis warna. Kemampuannya dalam membedakan warna dapat digunakan sebagai pemilih dan pengendali kerja pada beberapa perangkat kelistrikan. Untuk mengetahui manfaat sensor TCS300, sebuah penelitian dilakukan guna mengetahui fungsi sensor TCS3200 pada beberapa penggerak dan perangkat listrik. Pada penelitian ini dibuat sebuah aplikasi sensor TCS3200 dalam bentuk perangkat relay DC 5V (untuk memulai atau menghentikan penggerak listrik) dan beberapa perangkat elektronik. Alat ini menggunakan media dalam bentuk kartu warna sebagai input data. Kartu akan dibaca oleh sensor TCS3200, setelah itu data pembacaan akan diterima oleh mikrokontroler Atmega8535, kemudian hasilnya akan ditampilkan pada beberapa perangkat aplikasi seperti relay, LCD, speaker dan LED sebagai output. Sensor akan bekerja membaca warna dalam jarak 2,5 cm dari objek warna. Setelah melakukan penelitian, sensor TCS3200 dapat mendeteksi kartu warna yang telah disediakan. Berdasarkan program yang telah disusun, Sensor mampu membedakan 9 jenis warna dan membutuhkan waktu 1 - 2 detik untuk mengaktifkan output setelah input warna diberikan.
\end{abstract}

Kata Kunci

Sensor Warna, Atmega8535, Sensor TCS3200, Penggerak Listrik

1 Jurusan Teknik Elektro,Universitas Negeri Padang

Fakultas Teknik, Kampus UNP Air Tawar, Jl. Prof. Dr. Hamka, Padang

*mharun.rosyid64@gmail.com

Submitted : October 10, 2019. Accepted : November 11, 2019. Published : January 20, 2020. 


\section{PENDAHULUAN}

Seiring perkembangan zaman, berbagai macam teknologi telah diciptakan. Hal tersebut tentunya memiliki tujuan untuk mempermudah kehidupan manusia. Salah satu bidang yang berkembang adalah teknologi elektronika. Komputer sebagai bagian dari teknologi elektronika terus berkembang guna memenuhi kebutuhan manusia. Adanya kehadiran komputer telah mempermudah manusia dan meningkatkan evektivitas pekerjaan manusia. Komputer bekerja dengan memproses data dalam bentuk digital. Dimana data tersebut diproses oleh salah satu komponen komputer yang disebut prosesor.

Mikrokontroler merupakan salah satu jenis prosessor dan juga alat elektronika digital yang mempunyai masukan dan keluaran serta kendali dengan program yang bisa ditulis dan dihapus secara khusus, cara kerja mikrokontroler sebenarnya membaca dan menulis data. Mikrokokntroler juga merupakan komputer dengan chip yang digunakan untuk mengontrol peralatan elektronik [1]. ATmega8535 adalah mikrokontroler 8-bit berdaya rendah yang berbasis AVR dan menggunakan arsitektur RISC (Reduced Intruction Set Computing) yang disempurnakan. Dengan menjalankan instruksi dalam satu siklus clock, ATmega8535 mampu bekerja dengan mengoptimalkan konsumsi daya yang relatif kecil. Atmega8535 sendiri dapat bekerja pada tegangan antara 4,5 - 5,5 V DC [2]. Untuk memenuhi kebutuhan daya serta tegangan pada alat, digunakan catu daya atau power supply yang dapat memberikan tegangan 5V DC. Power supply merupakan sebuah perangkat penyedia tegangan untuk peralatan elektronika yang bekerja dengan prinsip mengubah tegangan pada jaringan distribusi transmisi listrik ke level yang diinginkan [3].

Sebagai pemroses data, mikrokontoler dapat mengidentifikasi pembacaan warna yang dapat dilakukan oleh sensor warna. Sensor yang dapat digunakan sebagai pembaca warna salah satunya adalah sensor TCS3200. Sensor ini diprogram untuk mengubah warna menjadi frekuensi yang tersusun atas konfigurasi silicon photodiode dan konverter arus ke frekuensi dalam IC (Integrated Circuit) CMOS monolithic yang tunggal [4]. Sensor ini dapat bekerja dengan membaca perbedaan frekuensi pada setiap warna. dengan menggunakan mikrontroler sebagai pemroses data, sensor ini dapat dimanfaatkan untuk mengidentifikasi berbagai hal.

Pada penelitian sebelumnya, telah dibuat beberapa bentuk perancangan aplikasi sensor TCS3200. Di tahun 2017, sebuah penelitian dengan judul "Sistem Pengidentifikasi Warna Bagi Penderita Buta Warna Berbasis Mikrokontroler" dilakukan dengan memanfaatkan aplikasi Sensor TCS3200 pada sebuah LCD 16x2. Alat ini dirancang agar dapat membaca 4 macam warna [5]. Pada penelitian lainnya, yaitu di tahun 2018 dibuat perancangan aplikasi sensor TCS3200 dengan judul "Alat Pendeteksi Warna Dengan Menggunakan Sensor TCS320 Berbasis Mikrokontroller Arduino Uno". Di penelitian ini juga dibuat sebuah mekanisme bentuk aplikasi sensor TCS3200 dalam bentuk LCD. Penelitian ini menghasilkan sebuah alat yang mampu membaca 8 jenis warna [6].

Untuk mengetahui lebih jauh manfaat dan fungsi dari sensor TCS3200, maka diperlukan sebuah penelitian dan perancangan yang menerapkan aplikasi sensor TCS3200. Dengan memanfaatkan kemampuan sensor TCS3200 dalam membedakan warna, maka dapat dilakukan pemilihan dan pengaturan dalam mengoperasikan penggerak listrik. Dengan kata lain, sensor warna dapat dimanfaatkan untuk melakukan pemilahan dalam pengoperasian berbagai macam perangkat yang bekerja menggunakan penggerak listrik, baik itu penggerak pada conveyor, penggerak pada mesin, dan berbagai perangkat dalam dunia industri. Pada perancangannya, dibuat bentuk aplikasi sensor TCS3200 dengan menggunakan Relay dan beberapa perangkat output serta menggunakan Atmega8535 sebagai pengendalinya. Relay memanfaatkan Prinsip Elektromagnetik untuk menggerakkan Kontak Saklar sehingga dengan arus listrik yang minim dapat menghantarkan listrik yang bertegangan lebih tinggi [7]. Oleh 
sebab itu, Relay akan digunakan sebagai saklar yang akan menghidupkan serta mematikan penggerak listrik. Sebagai objek aplikasinya, pada penelitian ini akan digunakan penggerak listrik berupa motor AC $220 \mathrm{~V}$.

Dalam menjalankan sistem alat, disusun beberapa komponen yang akan digunakan sebagai I/O (input dan output). Alat ini menggunakan sensor TCS3200 sebagai input dan beberapa output seperti relay, LED, speaker dan LCD. Sensor TCS3200 bekerja dengan memanfaatkan perbedaan frekuensi pantulan cahaya dari warna dasar RGB (Red, Green dan Blue), menggunakan relay yang dapat diaktifkan dengan tegangan 5V DC, memakai LED warna, memanfaatkan LCD 16x2 dan menggunakan IC ISD 2590 sebagai penghasil suara speaker. Sensor warna ini akan dioperasikan pada jarak 2,5 cm dari objek dan dalam kondisi pencahayaan yang minim guna mendapatkan hasil pembacaan yang akurat.

ISD2590 merupakan chip yang dapat menyimpan dan memutar suara. Sebagai media penyimpan suara, IC ISD2590 menyediakan port address yang digunakan sebagai alamat penyimpanan suara. Pada penamaannya, kode "ISD" dan "25" menandakan tipe dari IC, sementara angka "90" menandakan durasi total suara yang mampu disimpan. IC ini mampu menyimpan suara dengan total durasi selama 90 detik. Alat ini hanya berupa keping tunggal IC ,namun didalamnya sudah memuat berbagai perangkat tambahan yang dapat membantu dalam operasi perekaman dan pemutar ulang suara. Alat tambahan itu berupa oscillator, penguat microphone, Automatic Gain Control (AGC), filter suara, dan penguat untuk speaker, sehingga tidak memerlukan penguat tambahan untuk speaker lagi. Kelebihan lain dari alat ini adalah mampu dikoneksikan dengan perangkat microprossesor dan mikrokontroler. ISD2590 juga mempunyai memori khusus untuk menyimpan hasil rekaman suara [8]. Untuk lebih jelasnya, urutan I/O alat dapat dilihat pada bagian diagram blok .

Pada tulisan ini, akan dijabarkan proses penelitian mengenai aplikasi kerja sensor warna dalam menghidupkan dan mematikan penggerak listrik (motor listrik 220V AC). Mulanya di paparkan mengenai latar belakang dilakukannya penelitian dan pembuatan alat. Kemudian dilakukan pengkajian mengenai bagaimana cara sensor bekerja dalam membaca warna dan mengaktifkan penggerak listrik serta beberapa perangkat output. Setelah penelitian dilakukan, akan dipaparkan hasil pengujian alat dan kesimpulan mengenai penelitian ini.

Berdasarkan latar belakang yang telah di paparkan, maka dapat diidentifikasi masalah yang ada sebagai berikut (1) Bagaimana membaca warna objek menggunakan Sensor TCS3200 (2) Bagaimana menggunakan mikrokontroler ATmega8535 sebagai pemroses hasil pembacaan sensor Warna.(3)Bagaimana algoritma kerja aplikasi sensor TCS3200 penggerak listrik dan beberapa perangkat elektronika.

\section{METODE PENELITIAN}

Untuk merancang sistem alat, tentunya diperlukan sebuah metode perancangan alat. pada bagian ini akan dipaparkan secara ringkas mengenai gambaran alat, mulai dari input sensor, pengendali, hingga hasil output alat.

\section{Blok Diagram}

Pada bagian blok diagram pada Gambar 1, input akan dimulai dari pembacaan kartu warna pada sensor TCS3200. Hasil pembacaan akan masuk ke mikrokontroler kemudian akan dihasilkan output berupa LCD, LED, Speaker dan Relay. Untuk memperjelas hal tersebut, diagarm blok pada Gambar 1 akan memberikan gambaran I/O alat.

\section{Cara Kerja Alat}

Pada bagian program alat, diperlukan perancangan diagram alur atau flowchart guna memperjelas algoritma cara kerja alat. dengan adanya flowchart, maka dapat diketahui garis besar dari susunan program alat. Untuk informasi lebih lanjut mengenai gambaran algoritmanya, Gambar 2 menampilkan urutan flowchart alat. Dimulai dari inisialisasi alat, 
keseluruhan sistem alat mulai menyala dan sensor TCS3200 mulai melakukan pembacaan warna. Saat sensor tidak mendeteksi adanya kartu warna, maka layar LCD akan memberikan informasi bahwa warna tidak terdeteksi. Saat sensor mendeteksi adanya kartu warna, maka algoritma tanya "apakah terdeteksi warna" akan berjawaban "Y" (ya), yang berarti terdapat sebuah kartu warna terdeteksi. Saat hal ini terjadi, maka alat akan menampilkan beberapa output, yaitu LCD yang menampilkan informasi warna yang terdeteksi, data alamat akan dikirimkan ke ISD2590 untuk mengaktifkan speaker agar memberikan informasi dalam benuk suara, lampu akan aktif (sesuai dengan warna kartu yang terdeteksi), dan sebuah relay akan aktif. Setelah alat dinonaktifkan, urutan akan berakhir dan algoritma akhirnya selesai.

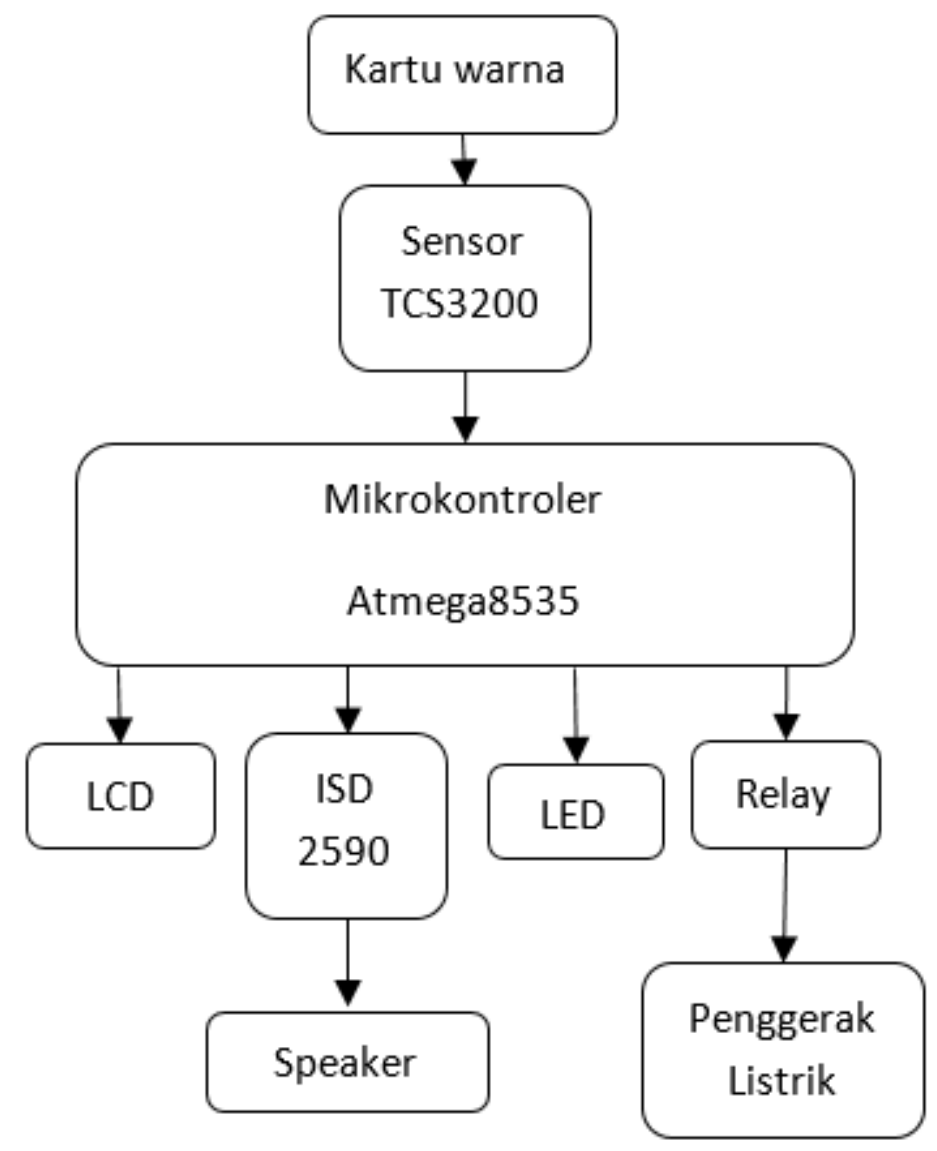

Gambar 1. Diagram Blok Alat

Dalam pemrogramannya, sensor TCS3200 menyediakan variasi skala perhitungan dalam membaca warna, skala tersebut antara lain pada 1:50, 1:5 dan 1:1 [9]. Pada Penelitian kali ini akan digunakan skala 1:5 dalam pembacaan warna, Sehingga hasil pembacaan pada alat (LCD atau layar informasi) nantinya akan berbanding 1:5 dengan nilai frekuensi yang dideteksi oleh sensor. Hal ini dilakukan guna mempermudah peneliti dalam memperoleh hasil pembacaan pada layar informasi.

\section{Perancangan Hardware}

Sebagai bagian dari perancangan, hardware juga menjadi peran penting dalam membentuk sistem alat. perancangan hardware di buat untuk menentukan perangkatperangkat, rangkaian elektrik serta mekanik yang akan digunakan pada alat. 


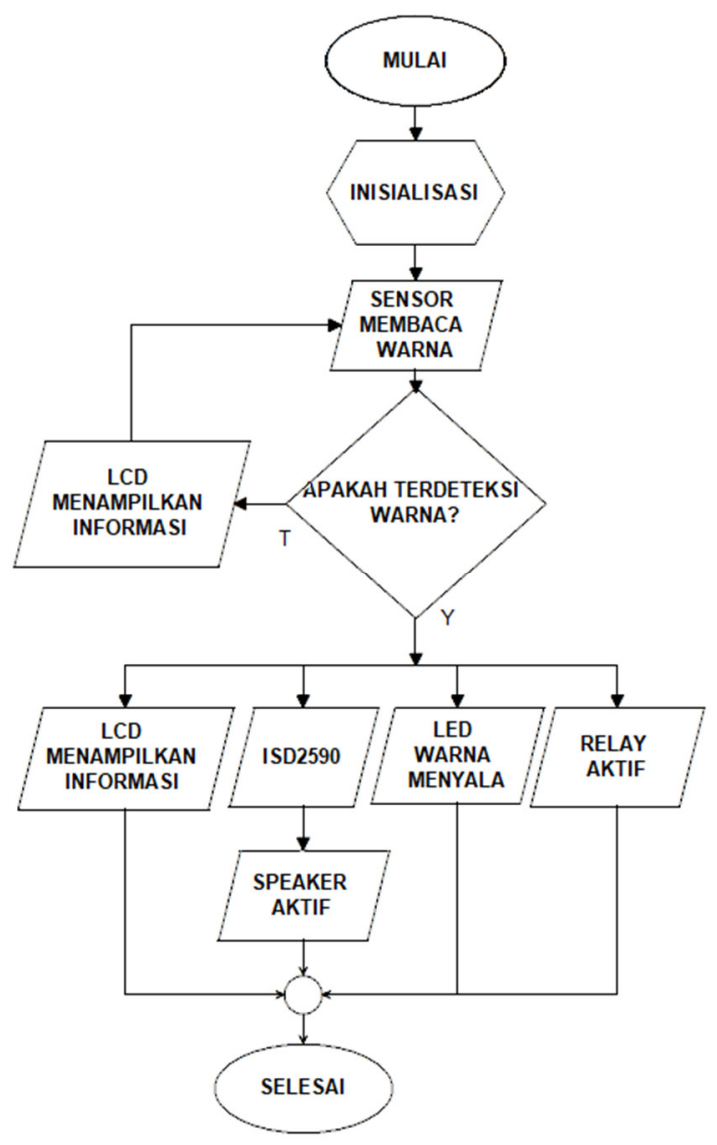

Gambar 2. Flowchart Alat

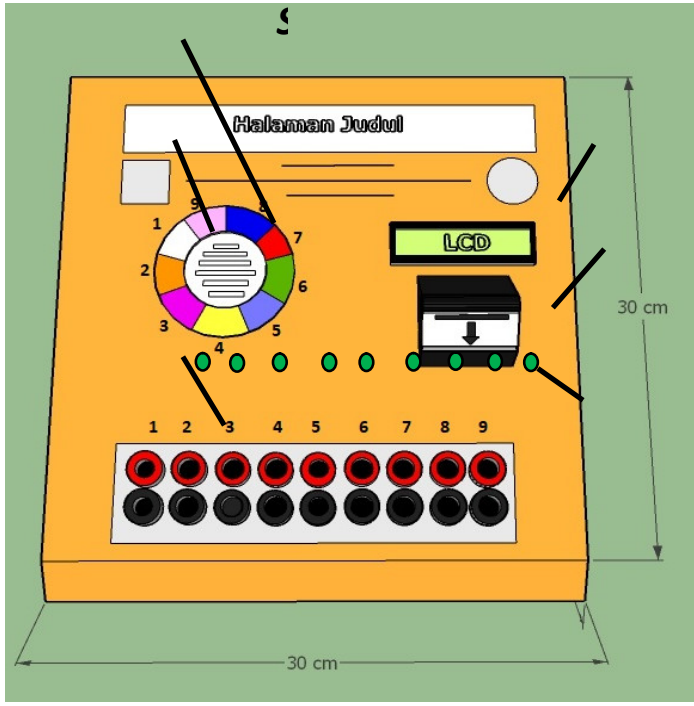

a

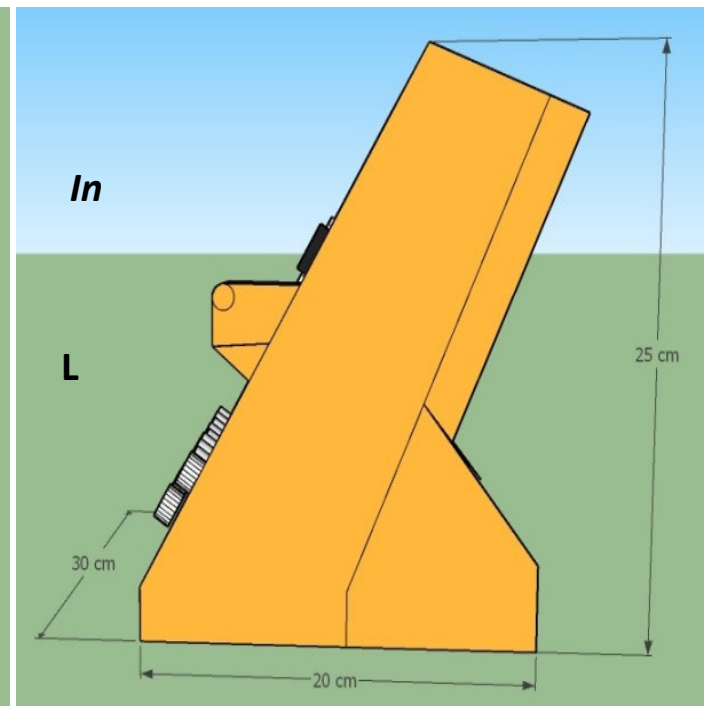

$\mathrm{b}$

Gambar 3. (a) Tampak Depan Alat dan (b) Tampak Samping Alat

\section{Perancangan Desain Alat}

Desain pada alat ini telah dibuat dengan beberapa penyesuaian. Hal tersebut mempertimbangkan bagian interface agar dapat dilihat dan digunakan dengan baik. Bahan yang digunakan sebagai wadah dan kerangka alat berupa serat kaca atau fiber glass. Gambar 3 menunjukkan desain alat. 
Pada bagian tampak depan alat, terdiri dari beberapa bagian output yang disusun dalam suatu interface. Alat ini dibuat dengan ukuran panjang sisi interface sebesar $30 \times 30 \mathrm{~cm}$. Layar LCD dipasang menghadap ke user atau pengguna agar informasi terlihat jelas. Bagian input dibuat berbentuk celah sesuai dengan input warna. pada bagian kirinya, terdapat speaker yang di sekelilingnya tersusun 9 buah LED warna. pada bagian bawah interface, terdapat susunan port yang merupakan bagian NC (Normaly Close) dari relay. Untuk memudahkan pengguna, pada bagian port tertulis angka-angka dan LED indikator yang menjadi tanda atau identitas dari warna yang terdeteksi.

2. Rangkaian Schematic alat dan Penggerak Listrik

Pada bagaian rangkaian, terdiri dari beberapa input dan output yang terhubung dengan beberapa perangkat. Sensor TCS3200 di pasang pada port mikrokontroler sebagai input dan output. Setiap pin pada sensor TCS3200 terpasang pada port B mikrtokontroler Atmega8535. Input yang masuk ke Mikrokontroler berasal dari keluaran frekuensi sensor, sementara output yang berasal dari mikrokontroler ditujukan untuk mengatur pemilihan input skala frekuensi dan mengatur pemilihan input photodioda pada pencahayaan pada LED sensor. Pada beberapa bagian pin, Chip ISD2590 di atur sebagai output pada port B dan port D mikrokontroler. port B digunakan sebagai pengatur start/stop chip, sementara port D di atur sebagai tempat akses alamat suara yang telah tersimpan. Pada chip ISD2590, terdapat juga beberapa pin yang difungsikan sebagai jalur input mikrofon, output speaker dan beberapa rangkaian lainnya. Output Relay dan LED pada alat ini di rangkai pada jalur port A dan pin C3 port $\mathrm{C}$ mikrokontroler. Untuk menghemat kapasitas penggunaan mikrokontroler, relay dan LED menempati posisi port yang sama. Sebagai bentuk aplikasi alat, digunakan 3 buah penggerak listrik atau motor 1 fasa 220 volt AC yang akan dihidupkan dan dimatikan menggunakan switch pada relay. Gambar 4 dan Gambar 5 di bawah menunjukkan rangkaian Schematic alat dan penggerak Listrik.

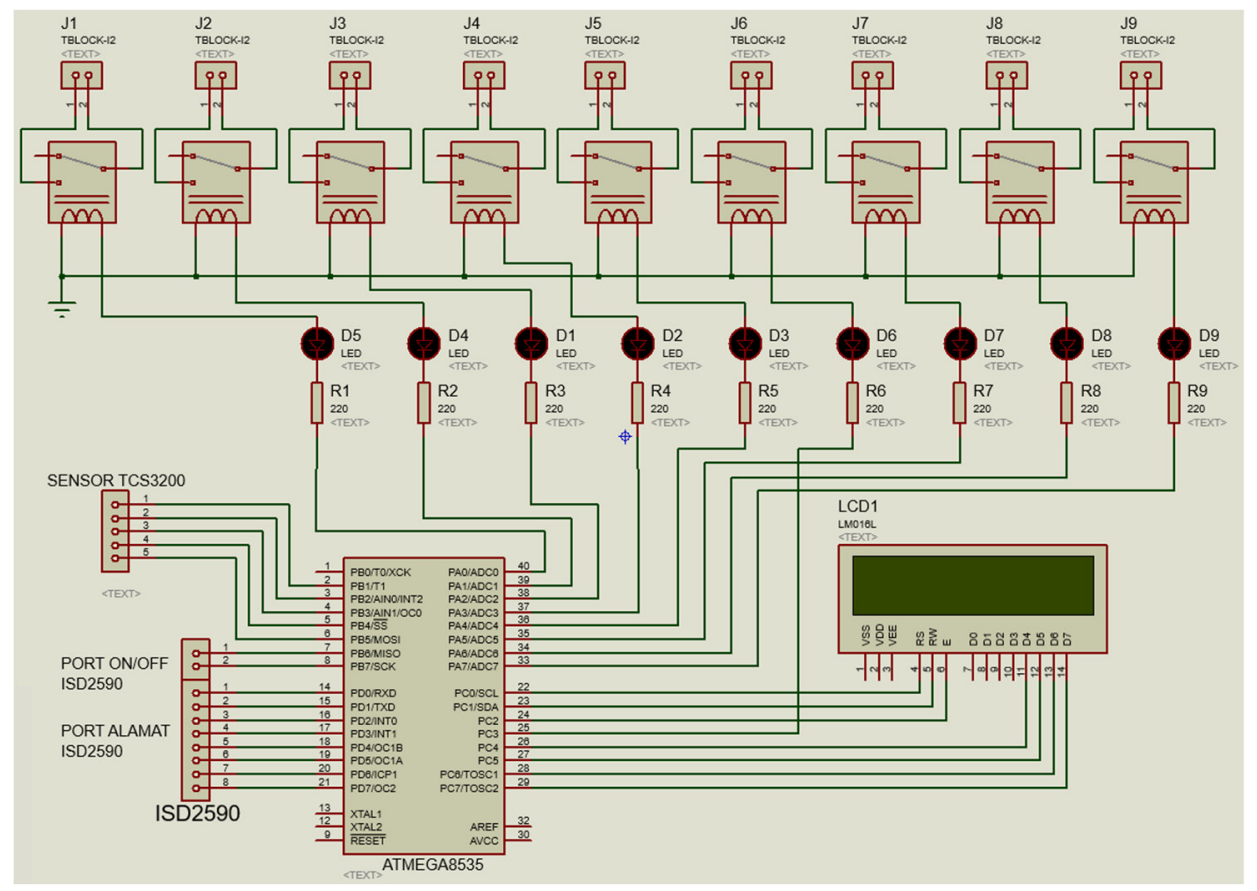

Gambar 4. Rangkaian Schematic Alat 


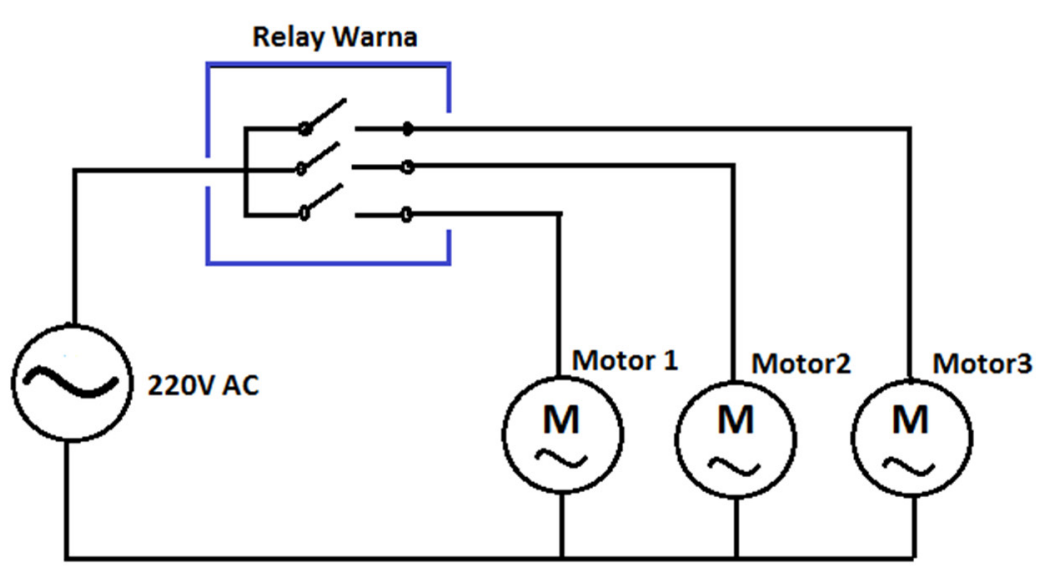

Gambar 5. Rangkaian Schematic Relay dan Penggerak Listrik

HASIL DAN PEMBAHASAN

Pada Hasil dan pembahasan, akan dilakukan beberapa pengujian dan analisa pada seluruh bagian input dan output alat. Analisa sensor alat dilakukan guna mengetahui apakah sensor berfungsi dengan baik sebagai input sesuai dengan yang direncanakan. Pembacaan sensor warna akan memberikan hasil berupa gelombang kotak atau freukensi yang berbedabeda pada tiap warna. Nilai pembacaan ini terdiri dari kombinasi 3 warna dasar, yaitu RGB (Red, Green Blue). nilai $R G B$ diperoleh saat melakukan kalibrasi sensor TCS3200. Nilai ini nantinya akan digunakan sebagai acuan dalam memilih warna. Pembuatan mekanik atau case dari alat telah dilakukan sesuai dengan perancangan desain yang telah direncanakan. Gambar 6 menunjukkan bentuk fisik dari alat.

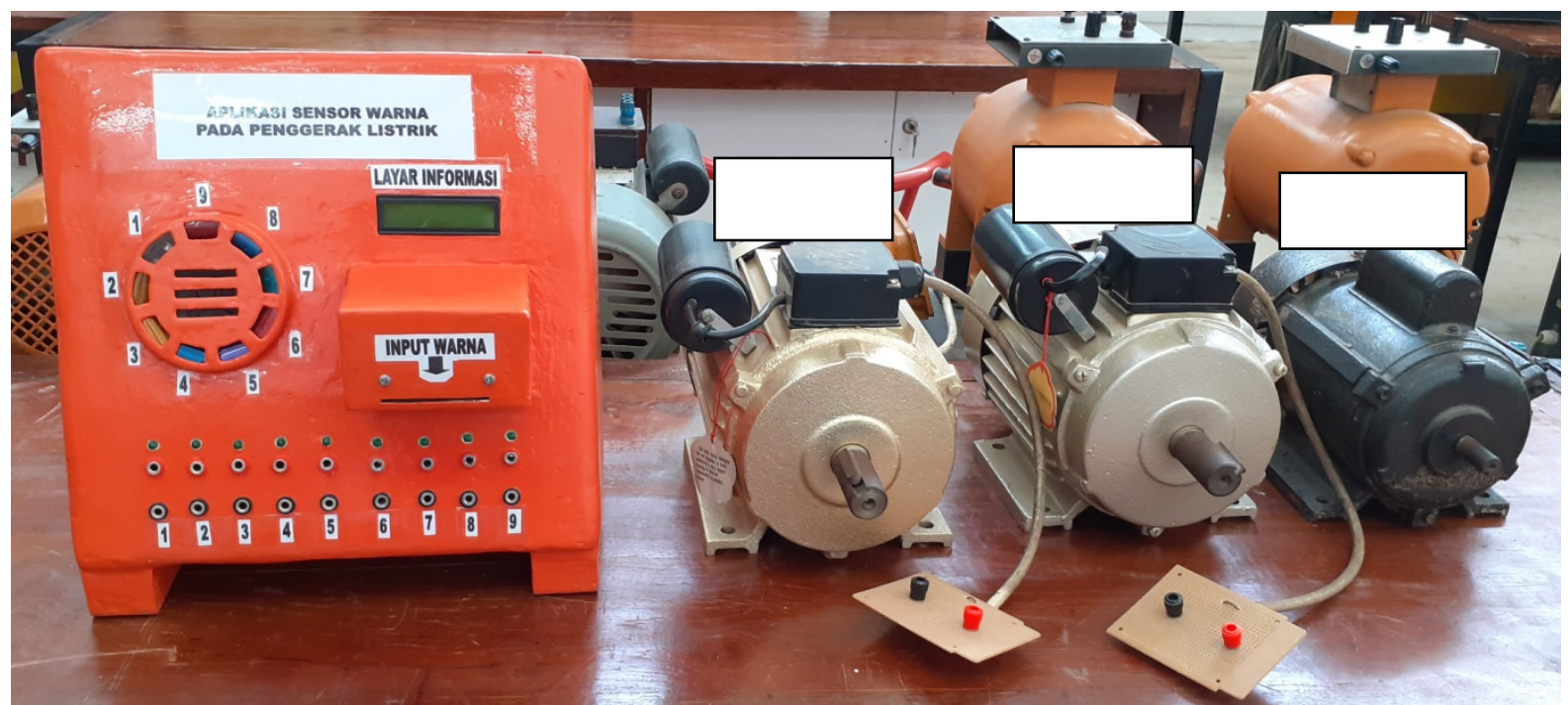

Gambar 6. Bentuk Fisik Alat dan Penggerak Listrik

\section{Hasil Pengujian Kerja Alat}

Untuk mengetahui hasil dari kinerja output, alat akan dioperasikan secara normal. Hal ini dimulai dari menghidupkan alat, mencoba input objek warna hingga menghasilkan output. Pengujian ini bertujuan untuk mengetahui apakah alat dapat befungsi dengan baik saat digunakan nanti. Setelah pengujian fungsi selesai, alat akan dinonaktifkan kembali. 
1. Pengujian Alat Tanpa Penggerak Listrik

Pada pengujian ini, dilakukan uji coba alat untuk membaca 9 macam kartu warna tanpa penggerak listrik. Di bagian ini akan dilihat respon semua output alat terhadap input 9 kartu warna yang diberikan serta jeda waktu kerja antara input dan output (dalam satuan secound atau detik). Tabel 1 menunjukkan hasil pengujian alat tanpa penggerak listrik.

Tabel 1. Hasil Pengujian Alat Tanpa Penggerak Listrik

\begin{tabular}{|c|c|c|c|c|c|c|}
\hline NO & Warna & Informasi LCD & Speaker & LED & Relay & Jeda Waktu (s) \\
\hline 1 & Putih & Putih & Aktif & Putih & Aktif & 2 \\
\hline 2 & Kuning & Kuning & Aktif & Kuning & Aktif & 2 \\
\hline 3 & Jingga & Jingga & Aktif & Jingga & Aktif & 1 \\
\hline 4 & Biru Muda & Muda & Aktif & Biru Muda & Aktif & 2 \\
\hline 5 & Ungu & Ungu & Aktif & Ungu & Aktif & 1 \\
\hline 6 & Merah Muda & Muda & Aktif & $\begin{array}{c}\text { Merah } \\
\text { Muda }\end{array}$ & Aktif & 1 \\
\hline 7 & Hijau & Hijau & Aktif & Hijau & Aktif & 1 \\
\hline 8 & Biru Tua & Tua & Aktif & Biru Tua & Aktif & 1 \\
\hline 9 & Merah & Merah & Aktif & Merah & Aktif & 1 \\
\hline 10 & Tanpa Kartu & Tidak Terdeteksi & Tidak aktif & Tidak aktif & Tidak aktif & 1 \\
\hline
\end{tabular}

2. Pengujian Alat Menggunakan Penggerak Listrik

Di bagian ini, akan dipaparkan hasil pengujian alat menggunakan penggerak listrik. Tabel 2 menunjukkan hasil pengujian alat menggunakan penggerak listrik. Alat akan diberikan 3 buah input warna (Merah, Biru Tua dan Jingga) untuk menghidupkan dan mematikan 3 buah motor 220V AC. Saat data kartu warna dimasukkan, salah satu motor menyala dan beberapa perangkat output aktif. Warna merah menghidupkan motor 1, warna biru muda menghidupkan motor 2 dan warna jingga menghidupkan motor 3. Apabila input warna tidak ada (input $=0$ ) maka motor dan beberapa perangkat output lainnya akan berhenti atau tidak aktif.

Tabel 2. Hasil Pengujian Alat Mengunakan Penggerak Listrik

\begin{tabular}{|c|c|c|c|c|c|c|}
\hline NO & Warna & LCD & Speaker & LED & Relay & Motor \\
\hline 1 & Merah & $\begin{array}{c}\text { "Terdeteksi Warna } \\
\text { Merah" }\end{array}$ & Aktif & Menyala & Aktif & Motor 1 Hidup \\
\hline 2 & $\begin{array}{c}\text { Biru } \\
\text { Muda }\end{array}$ & $\begin{array}{c}\text { "Terdeteksi Warna } \\
\text { Biru Muda" }\end{array}$ & Aktif & Menyala & Aktif & Motor 2 hidup \\
\hline 3 & Jingga & $\begin{array}{c}\text { "Terdeteksi Warna } \\
\text { Jingga" }\end{array}$ & Aktif & Menyala & Aktif & Motor 3 hidup \\
\hline 4 & $\begin{array}{c}\text { Tanpa } \\
\text { Warna }\end{array}$ & $\begin{array}{c}\text { "Warna Tidak } \\
\text { Terdeteksi" }\end{array}$ & Non-Aktif & Mati & $\begin{array}{c}\text { Non- } \\
\text { Aktif }\end{array}$ & $\begin{array}{c}\text { Motor } 1,2, \& 3 \\
\text { mati }\end{array}$ \\
\hline
\end{tabular}

3. Hasil Pembacaan frekuensi RGB 
Saat melakukan kalibrasi, hasil pembacaan sensor berupa nilai RGB yang berubah-ubah setiap waktu. Oleh karena itu, nilai tertinggi dan terendahnya akan di ambil sebagai sample untuk mengetahui panjang range hasil pembacaan sensor. Tabel 3 akan menunjukkan hasil pembacaan RGB pada layar informasi (dengan skala 1:5 dengan hasil pembacaan frekuensi sensor). Untuk mengetahui nilai rata-rata frekuensinya, digunakan rumus pencarian nilai rata-rata RGB warna.

\section{Tabel 3. hasil pembacaan frekuensi RGB pada layar informasi}

\begin{tabular}{|c|c|c|c|c|}
\hline \multirow{2}{*}{ NO } & \multirow{2}{*}{ Jenis Warna } & \multicolumn{3}{|c|}{ Nilai Rata-rata RGB } \\
\cline { 3 - 5 } & & $R$ & $G$ & B \\
\hline 1 & Merah & 98 & 258,5 & 154,83 \\
\hline 2 & Hijau & 175 & 145,5 & 173,5 \\
\hline 3 & Biru Muda & 133 & 74,5 & 46 \\
\hline 4 & Jingga & 57,5 & 116,5 & 138 \\
\hline 5 & Kuning & 50,5 & 61 & 78,5 \\
\hline 6 & Biru Tua & 162 & 126,5 & 80 \\
\hline 7 & Ungu & 133 & 170,5 & 94 \\
\hline 8 & Merah Muda & 53 & 82,5 & 62,5 \\
\hline 9 & Putih & 50 & 49,5 & 38,5 \\
\hline
\end{tabular}

Catatan : nilai $R G B$ pada setiap sensor dapat berbeda, hal ini dapat dipengaruhi oleh jarak pembacaan dan kondisi pencahayaan pada lingkungan sensor.

$$
\text { Rata }- \text { rata RGB }=\frac{\text { Jumlah data Range RGB }}{\text { Panjang Range RGB }}
$$

Untuk mengetahui ketepatan pembacaan warna dari sensor TCS3200, maka dilakukan perbandingan antara frekuensi dasar warna dasar (merah, hijau dan biru) yang terbaca pada Sensor dengan frekuensi warna sebenarnya. Nilai frekuensi dasar warna merah adalah 415 $\mathrm{Hz}$, warna hijau bernilai $523 \mathrm{~Hz}$ dan warna biru bernilai $659 \mathrm{~Hz}$ [10]. Tabel 4 menunjukkan perbandingan antara frekuensi warna dasar terukur dengan frekuensi sebenarnya.

Tabel 4. perbandingan antara frekuensi warna dasar terukur dengan frekuensi sebenarnya.

\begin{tabular}{|c|c|c|c|}
\hline No & Warna & Frekuensi Sebenarnya & Frekuensi Terukur Pada Alat \\
\hline 1 & Merah & $415 \mathrm{~Hz}$ & $490 \mathrm{~Hz}$ \\
\hline 2 & Hijau & $523 \mathrm{~Hz}$ & $727,5 \mathrm{~Hz}$ \\
\hline 3 & Biru & $659 \mathrm{~Hz}$ & $230 \mathrm{~Hz}$ \\
\hline
\end{tabular}

\section{SIMPULAN}

Berdasarkan penelitian dan pengujian yang telah dilakukan, dapat disimpulkan bahwa alat dapat bekerja dalam mendeteksi 9 kartu warna yang telah disediakan. Saat diuji, warna merah, biru muda dan jingga dapat menghidupkan serta mematikan penggerak listrik. Bagian LCD dapat menampilkan informasi sesuai dengan kondisi warna yang dideteksi sensor. 
Bagian LED, speaker dan relay dapat menyala sesuai dengan algoritma hasil pembacaan sesor. Namun saat dibandingkan dengan frekuensi warna sebenarnya, sensor TCS3200 terbilang kurang Akurat. Hal ini dikarenakan hasil pembacaan frekuensi pada sensor TCS3200 dapat berbeda dengan frekuensi warna sebenarnya, tergantung pada posisi, jarak dan pencahayaan pada sensor.

\section{DAFTAR RUJUKAN}

[1] Sumardi. 2013. Mikrokontroler - Belajar AVR Mulai Dari Nol. Semarang:Graha Ilmu.

[2] Datasheet ATmega8535.

pdf1.alldatasheet.com/datasheet-pdf/view/164169/ATMEL/ATMEGA8535.html. (diakses 23 Februari 2018).

[3] Rohmatullah. 2015. "Pengertian dan Fungsi Catu Daya Secara Umum". http://rohmattullah.student.telkomuniversity.ac.id/pengertian-dan-fungsi-catu-dayasecara-umum/ (diakses 27 Maret 2018).

[4] Ardan, Dani. 2016. "Tutorial Penggunaan Sensor Warna Tcs230/TCS3200”, http://www.belajarduino.com/2016/12/tutorial-penggunaan-sensor-warna-tcs230.html (09 Februari 2018).

[5] Tamar, Abdiawan. 2017. "Sistem Pengidentifikasi Warna Bagi Penderita Buta Warna Berbasis Mikrokontroler". Makassar: Universitas Islam Negeri Alauddin Makassar.

[6] Siregar, Nurul Fatimah. 2018. "Alat Pendeteksi Warna dengan Menggunakan Sensor TCS320 Berbasis Mikrokontroller Arduino Uno". Medan: Universitas Sumatra Utara.

[7] Kho, Dickson. 2013. "Pengertian Relay dan Fungsinya". https://teknikelektronika.com/pengertian-relay-fungsi-relay/ (diakses 8 Mei 2019).

[9] Datasheet Sensor TCS3200. https://www.parallax.com/product/28302. (diakses 23 Februari 2018).

[8] Suwito. 2012. "Rancang Bangun Alat Bantu Peringatan Batas Laju Kendaraan Umum Berbasis Mikrokontroler Avr Dan Komunikasi Infra Merah". Surabaya: Institut Teknologi Sepuluh Nopember Surabaya.

[10] TigerColor."Color Theory, Tutorials \& Resources: Welcome to The Color Lab". http://www.tigercolor.com/color-lab. (diakses 7 November 2019).

\section{Biodata Penulis}

Risfendra, S.Pd, M.T, Ph.D, lahir di Riau, 13 Februari 1979. Sarjana Teknik Elektronika di Universitas Negeri Padang, lulus tahun 2004, S2 Teknik Sistem Pengaturan, ITS tahun 2008. S3 Shouten Taiwan University, of science and technology, Taiwan tahun 2017. Staf pengajar pada Jurusan Teknik Elektro FT UNP sejak tahun 2005 - sekarang.

M. Harun Rosyid, dilahirkan di Padang, 15 September 1995. Menyelesaikan studi DIV Teknik Elektro Industri pada Jurusan Teknik Elektro Fakultas Teknik Universitas Negeri Padang. 